\title{
GRADUATION DETERMINANTS OF PRODUCTIVE SAFETY NET PROGRAM BENEFICIARY HOUSEHOLDS: A LOGISTIC ANALYSIS, TIGRAI-ETHIOPIA
}

\author{
YIBRAH HAGOS GEBRESILASSIE' \\ Adigrat University, Ethiopia
}

\begin{abstract}
Household food security issues have become the concern of international communities as well as national government of Ethiopia. Social safety nets (like Productive Safety Net Program in Ethiopia) are programs that offer protection to poor rural people by providing income through transfer programs and employment opportunities. The main objective of this study was to identify the major graduation determinants of Productive safety Net Program beneficiary rural households using a logistic regression technique from a total of 400 sample respondents using Eastern zone of Tigrai regional national state, northern Ethiopia, as case study site. The researcher was initially identified about sixteen predicting factors of which just ten of them were found to be statistically significant, and all exhibited the expected signs. Regression results revealed that an introduction to integrated agricultural package make use of, male-headed household, age squared of the household head, educational status of the household head, saving culture, male adults, non-government organizations followup, access to credit, access to petty trading and irrigation have led productive safety net program beneficiary households to have more probability of graduation. Finally, it is recommended that assisting farming rural households to diversify and expand their sources of income in order to be able to meet their minimum food requirement and graduate soon through the provision of integrated agricultural packages. Besides, program participants should be followed up by non-government organizations and highly engaged in petty trading to graduate sooner, boost their income and food secure.
\end{abstract}

\section{JEL CLASSIFICATION \& KEYWORDS}

- 012 Q18 BENEFICIARY - FOOD SECURITY " GRADUATION $=$ LOGISTIC ANALYSIS $=$ PROGRAM $\approx$ TIGRAI

\section{INTRODUCTION}

In recent times, the global focus has been on food security and poverty alleviation. This is being made in response to the increasing food insecurity and poverty in the world. The incidence of food insecurity and poverty is devastating particularly in the developing countries and in terms of food insecurity; 852 million people worldwide are still chronically underfed. In Africa, an estimated 200 million (27.4 percent) people are famished (Babatundeet al., 2007).

Drought, environmental degradation, population pressure, limited access to services, shortage of farmland, lack of productive assets, low input and subsistence agricultural practices are the most prominent causes of food insecurity problems in rural areas of Ethiopia. As a result, more than 38 percent of the rural households fall below the food poverty line and 15 percent of the rural population in Ethiopia reported that they experience a food gap of greater than four months (MoARD, 2007). Ethiopia is recognized as facing the greatest and most intractable problems in addressing 'yibhag@gmail.com food insecurity and achieving more sustainable livelihoods for its population. Recognizing this fact, the government initiated and formulated a development strategy known as Productive Safety Net Program in 2005 with the objective to provide transfers to the food insecure population in chronically food insecure areas in a way that prevents asset depletion at the household level and creates assets at the community level (Gilligan et al., 2006).

Productive Safety Net Program, PSNP, replaced the emergency humanitarian appeal system as the chief instrument. The program initially assisting about 5 million chronically food-insecure people in rural Ethiopia in about 262 chronically food insecure Woredas were targeted in the year 2005 which was scaled up to reach 8 million in 2006. The mode of payment was food and/or cash (Ethiopia PSNP, 2006). The program has been established to alleviate food insecurity. It is a formal program meant to benefit individuals and households who are chronically food insecure, unable to work, or experience temporary decline in purchasing power by providing them with income or a substitute for income. Such programs include cash and in-kind transfer programs, subsidies, and labor-intensive public works (Nigussa and Mberengwa, 2009). The program is planned to be implemented for five years, at the end of which Productive Safety Net Program beneficiaries who have received predictable transfers and complementary interventions throughout the program period will be expected to graduate out of dependence on external support, except during food crises (Samuel, 2006 and Ethiopia PSNP, 2006).

Graduation of Productive Safety Net Program is the ultimate goal of the program and will result in the reduction of the number of households requiring external food aid and assistance. As community assets are built and are linked to other agricultural and income generating programs family assets are protected and can actually increase. After a family's assets grow to an appropriate level, graduation from the Productive Safety Net Program will occur (Arega, B., 2012).

Tigrai regional national state is one among the regions identified to be benefited from the program. The Program is intended to protect the poorest section of the society or those who, as a result of shocks, find themselves temporarily below a given welfare level. Based on the national PSNP, the regional government has adopted the program with the purpose to help bridge the income gap of chronically food insecure households. Almost 911,451 rural community inhabitants in 31 districts (Woredas) have been identified as target for both public work and direct support Program beneficiaries (TFSCO, 2008).

\section{Statement of the problem}

The study area, Eastern zone of Tigrai regional national state, like many other drought-prone and vulnerable areas of the region, is distinguished by its frequent drought and food insecurity. This shows that the situation of food 
insecurity in the area has overwhelming to the poorest of the poor and majority of the rural households are beneficiaries of the ongoing Productive Safety Net Program. Therefore, the study helps to investigate graduation determinants of Productive Safety Net Program.

These people are very vulnerable to the negative consequences of any variability in rainfall or other negative events. During an emergency situation their ability to survive depends on the mining of their already limited capital and assets including, physical assets (tools and oxen), natural assets (land and water) and human capital (mainly labor). The mining of assets occur when families take last resort actions such as taking children out of school, or selling productive assets and household goods in order to survive. These families must rebuild their capital and assets to become productive again after the drought (shocks) has passed; consequently, the economic impacts of a crop failure are long-term and result in lifelong reductions in earnings. With each shock, families and communities become less able to cope and fall farther into food insecurity (Andrew, B., 2008).

The Productive Safety Net Program alone is aimed at asset protection and cannot therefore be expected to bring graduation from the program. And yet the program implementation manual states that graduation is the key goal of the program. This creates challenges for effective management of the program since it means that achievement of the key goal of the PSNP is not within its control; the PSNP can only be a contributor to graduation, not its sole driver. It also means that the success of PSNP depends on the performance of other programs (Slater et al., 2006).

PSNP together with other food security program will reduce household food insecurity; raise consumption levels, encourage households to engage in production and investment through enhanced access to credit, increased use of modern farming techniques and entry in to non-farm own business activities (Gilligan et al., 2006). While this is valuable information, and there are few studies on impact and graduation determinants of PSNP (Yibrah, H., 2010 and Gilligan et al., 2006) and a little attempt was done by Ashenafi (2011), but the study did not consider the management aspect who follow up the program (PNSP), inflation was not due considered while evaluating bench mark for program graduation and the conversion factor to determine graduation as bench mark. Albeit graduation is one of the main goals of the program, findings however; did not yet identify the major graduation determinants of Productive Safety Net Program.

Despite the burgeoning focus on Productive Safety Net Program on the part of both government and NGOs, independent and comprehensive assessments on graduation determinants of PSNP beneficiaries have been relatively limited. Most of the studies focus mainly on impact of the program. Therefore, with this knowledge gap in mind, the researcher was interested to identifying the major graduation determinants of PSNP beneficiaries using binary logistic regression techniques.

\section{Objectives of the study}

The overall objective of the study is to envisage graduation determinants of Productive Safety Net Program Beneficiary Households of Eastern zone of Tigrai regional national State, northern Ethiopia. More specifically:

- To identify the major graduation determinants of Productive Safety Net Program beneficiary households;
- to assess whether male or female-headed PSNP beneficiary households graduate sooner and

- to recommend policy implications based on the empirical findings of the study.

\section{Research hypothesis}

The following research questions have been forwarded:

- What are the major graduation determinants of PSNP beneficiary households?

- Will male-headed graduate more rapidly than femaleheaded PSNP beneficiary households or vice versa?

\section{Literature review}

\section{Definition of important terms}

Graduation is a two stage process. The first is graduation from the PSNP and the second is graduation from the Food security Program. Thus, here in this study graduation from the PSNP was the main focal point of the researcher. Graduation can be defined as "A household has graduated when in the absence of receiving PSNP transfers it can meet its food needs for the year or 12 months and is able to withstand modest shocks." This state is described as being 'Food Sufficient' (MoARD, 2007).

Self-graduation is when a household voluntarily leaves the PSNP. This occurs when household members have 'more valuable things to do with their time' than participate in the PSNP. For example, a household may cease to participate in the Program if its members can earn a higher wage through wage employment or the labor investment in own production is more valuable than time spent participating in the public works (lbid).

\section{Graduation benchmarks and indicators}

The benchmark describes the level of assets a food sufficient household is likely to have. When the status of a household's assets reaches this level, the household is no longer eligible for the Program. Until this point, a household remains eligible to participate in the PSNP and cannot be taken off the Program (MoARD, 2007).

Several other potential criteria could be considered for graduation, including:

- Asset based criteria, collecting information on the number or replacement value of a basket of identified productive assets owned, including animals, land, and equipment;

- time based criteria, graduating households that have not experienced food shortages for three years;

- consumption or nutrition based criteria, such as diet diversity, daily food consumption patterns, or nutritional status; and/or

- subjective or intangible criteria as defined by the perception of households within participating communities.

As has been mentioned in Arega (2012) it has been suggested that land, livestock and some productive equipment as indicator of program graduation. The same authors also added that PSNP beneficiary households owned at least one ox, four goats, one cow, consume from own production not less than 9 months, 2-3 meals per day are the benchmarks used for program graduation. Hoddinott (2011) has also added that indicators such as pair of ox and milking cow transformed from thatched houses to corrugated iron sheets and who can meet his/her food gaps better than others. 
Using assets as the basis for graduation would allow communities to remain fully involved in the monitoring process, because household asset ownership is well known throughout the community and asset information is easy to collect (PSNP-PIM, 2007). Once the individual asset holding of households is computed using per adult equivalent, and the asset value of PSNP beneficiary households is 5600.00 Eth. Birr per capita per annum from all resources owned. It'll taken as a benchmark for graduation and those beneficiaries having a total income greater or equal to this yardstick criterion are graduates (food self-sufficient) and could be regarded as a PSNP beneficiary graduate and were assigned a value of 1 while PSNP beneficiary households experiencing per capita per annum asset deficit mentioned above were regarded as non-graduates and were assigned a value of 0 .

\section{PSNP Graduate Households}

The binary logistic regression results showed that engagement in non-farm activities can enhance the graduation of program beneficiary households. The regression result indicated that an increase in the participation of non-farm activities by one unit the odds ratio of being program graduate increases by a factor of $0.312(P<0.05)$. Total production is another determinant variable helps to graduate households from productive safety net program. Being other variables constant, an increase of total production by one unit increases the probability of the households to graduate from the program by a factor of $1.59(P<0.05)$. Building assets especially the livestock sector enhances the graduation of the households. The regression result revealed that an increase of one unit of livestock, the probability of the odds ratio to graduate from program increases by a factor of $1.15(P<0.01)$ Arega, B., (2012).

Ashenafi (2011) has conducted a study on determinates of PSNP beneficiaries though his study did not consider inflation rate in calculating the graduation benchmark, and program follow up while doing his research. However, some of the factors that he has considered to be factor for graduation determinants of productive safety net program beneficiary households were found to be similar to the findings of this study.

\section{Data and methodology}

Research Design: Primary data was mainly employed and secondary data were also used from various outlets to supplement the data. Information was mainly collected concerning the PSNP beneficiary households and the study area was selected based on program coverage and then was stratified based on administration zones (government and non-government managed areas). Three Woredas from each administrative type have been selected and two tabias from each Woredas were also selected randomly. A logistic regression technique was employed to identify the major graduation determinants of PSNP beneficiary households. Finally, a total of 400 Productive Safety Net Program beneficiary rural households were selected using systematic random sampling procedure.

Data Analysis Techniques: Both Descriptive statistics like mean, frequency, percentages, etc and Econometric models through Statistical Package for Social Science (SPSS) and STATA were mainly employed to analyze the collected data on graduation determinants of productive safety net program beneficiary households.

Model Specification: A binary Logistic Regression model was employed to identify the major graduation determinants of PSNP at the household level. The dependent variable (dichotomous variable) assumed two values (1 for PSNP graduate and 0 otherwise) whereas the independent variables assumed any value, both continuous and categorical variables. Hence, a binary dependent variable logit regression model following Damodar N. Gujirati, Dawn C. Poter and SangeetharGunasekar (2009) and Woodridge (2009) was specified as below and used.

$$
\operatorname{Pr}\left(Y_{i}=1 \mid x\right)=\frac{e^{\alpha+\beta} X_{i}}{1+e^{\alpha+\beta} X_{i}}
$$

where: $Y_{i}=$ the $i^{\text {th }}$ observation response which have two outcomes ( $1=$ for PSNP graduates and 0 otherwise), $X_{i}=$ factors that affect household's graduation of PSNP, and $\alpha=$ the constant term and $\beta$ 's are the coefficient of the variables (vector of parameters to be estimated).

Key Findings on major determinants of Productive Safety Net Program graduates

A binary logistic regression model was employed to identify the major determinant $s$ influencing PSNP beneficiary households' graduation. The dependent variable was dummy (program graduates) and those who graduates were designated as Yes and valued 1 and No valued as 0 . A total of fifteen predictor variables were selected to explain the dependent variable (program graduates), but only ten among the predictor variables were found to be statistically significant, and all exhibited the expected signs (TABLE 2).

$\mathrm{Li}=\mathrm{G}\left(\beta_{0}+\beta_{1}\right.$ creditaccess $+\beta_{2}$ literacy $+\beta_{3}$ Irrigableland $+\beta_{4}$ age of $\mathrm{HH}+\beta_{5}$ followup $+\beta_{6}$ Sex of $\mathrm{HH}+\beta_{7}$ Programspan $+\beta_{8}$ Intgagripackage $+\beta_{9}$ Maleadult $+\beta_{10}$ Femaleadult $+\beta_{11}$ Inlandholding $+\beta_{12}$ pettytrading $+\beta_{13}$ savingexperience $+\beta_{14}$ Totproduction $+\beta_{15}$ Familysize $+\beta_{16}$ Livestockholding $=G\left(\beta_{0}+x_{i} \beta_{0}\right)$

Where $\mathrm{G}$ is a function taking on values strictly between zero and one: $0<G(z)<1$, for all real numbers, $z$. This ensures the estimated response probabilities are strictly between zero and one (Woodridge, 2009).

\section{Results and discussion}

The following table points out that the descriptive mean statistics of the sample respondents.

\begin{tabular}{|l|l|l|l|l|}
\hline Table 1: Descriptive mean statistics \\
\hline Variables & $\begin{array}{l}\text { PSNP } \\
\text { Graduates }\end{array}$ & $\begin{array}{l}\text { PSNP-Non } \\
\text { Graduates }\end{array}$ & $\begin{array}{l}\text { Mean } \\
\text { Difference }\end{array}$ & t-value \\
\hline Age square & 46.56 & 47.96 & 1.40 & 0.68 \\
\hline $\begin{array}{l}\text { Tlu (exluding } \\
\text { oxen) }\end{array}$ & 5.42 & 0.46 & -4.95 & $-4.50^{*}$ \\
\hline Oxen & 1.75 & 0.07 & -1.69 & $-5.43^{*}$ \\
\hline Inlandholding & 2.57 & 2.58 & 0.01 & 0.36 \\
\hline Irrigableland & 0.58 & 0.08 & -0.49 & $-3.89^{*}$ \\
\hline Maledult & 3.8 & 1.82 & 1.26 & $3.21^{*}$ \\
\hline Femaleadult & 2.10 & 3.21 & -1.11 & 1.021 \\
\hline Totproduction & 2.57 & 2.21 & 0.36 & -1.15 \\
\hline $\begin{array}{l}{ }^{*}, * * \\
\text { Not } \text {, Significant }\end{array}$ significant at 1, 5, \& 10 percent, respectively and NS $=$ \\
\hline Source: Author \\
\hline
\end{tabular}

To begin with the descriptive analysis of the research study, findings of the study indicated that 70 percent of the program participants were male headed while the rest were femaleheaded. This shows that most of the program participants are highly dominated by male-headed households. Thus, 
male-headed households graduate sooner than that of the female-headed households due to the fact that the male-headed households might engage in other sources of income that enable them boosting their income. Statistically, the mean percentage difference between male and femaleheaded graduates was significant at less than 1 percent level of significance $(2=51.22)$. Out of the total sample respondents 65 percent of them were literate while the rest 35 percent of them were illiterate. The findings revealed that literates have the probability of graduating sooner than that of the non-literate households. The descriptive analysis indicates that a household with better educational status relative to the others who did not, have higher probability of graduating. Statistically, there was mean difference in education status between literate and non-literate household head at less than 5 percent level of significance. The result again revealed that those who have access to credit service have high probability of graduating by investing in different developing activities.

About 95 percent of the sample respondents were engaged in various integrated agricultural packages. Integrated agricultural packages provides various alternatives to the households so that to pull out themselves from poverty. About 100 percent of the graduates and 85 percent of the non-graduates were participating in the integrated agricultural packages. The percentage difference between the graduates and the non-graduates were statistically significant at less than 1 percent level of significance. The result of the findings revealed that the family size and graduation from PSNP to be negatively correlated. On average, the non-graduates (5.1) had larger family members than graduates (4.02). The combined average family size for both graduates and non-graduates of the program is 3.56 . The mean difference in the family size between graduates and non-graduates of the program was not statistically significant. The mean age squared of the sample respondents were found to be 46.5 years. The mean ages squared of the graduates were 46.56 years while the non-graduates were 47.96 years. Statistically, there was no significant difference between graduates and nongraduates. Program participants who have more of male adults increased the probability of graduation than those households with a few male adults. The more the male adults they have, participants can reduce the households' benefits of the program as program beneficiaries. Statistically, there was significant difference in the mean male adult of program participants between graduates and non-graduates at less than 10 percent level of significance. The average cultivated land holding size of graduates was less than 0.25 hectares whereas that of the non-graduates was 0.21 hectares. The mean difference of the farm size between the graduates and non-graduate was not statistically significant.

Out of the total sample respondents 60 percent of them were exercising saving in financial institutions. Program participants were highly aware in saving philosophy because they have got trainings from the government on how to save and why to save as a result of participants have attempting saving activities in a better way than earlier and helps to graduate. Follow-up was used as a dummy variable 1 areas followed -up by NGOs and 0 otherwise. Program participants who were administered by the NGOs (REST) have had more probability of graduation than government administered program beneficiaries. This might be due the fact that there were proper follow-up or program management by NGO (REST)) and participants were well informed about graduation in relation to participants followed-up by government. Statistically, there was significant mean difference between NGOs administered and that of the government administered program participants at 5 percent level of significance.

The mean difference of the access to irrigable land between the graduates and non-graduates of program participants was statistically significant at less than 5 percent. This result also indicates that access to irrigable land and program graduation is correlated positively.

A household with four years of benefit from the program have had high probability of graduation from the PSNP than a household with three years of program benefit. All the sample respondents have had three and four years of program benefit and those who have stayed in the program for four years have had more probability to graduate from the PSNP. Statistically, there was a significant mean difference in years of program benefit between graduates and non-graduates of PSNP beneficiary households at less than 5 percent level of significance.

\begin{tabular}{|c|c|c|}
\hline Predictor Variables & Marginal Effect coefficient & $\mathrm{P}>|\mathrm{z}|$ \\
\hline Sex of $\mathrm{HH}$ & 0.371 & $0.823 \mathrm{NS}$ \\
\hline Age of $\mathrm{HH}$ & 0.377 & $0.779 \mathrm{NS}$ \\
\hline Inlandholding & 0.101 & $0.061 \mathrm{NS}$ \\
\hline Irrigableland & 0.390 & $0.001^{*}$ \\
\hline Intgagripackage & 0.530 & $0.031^{* * *}$ \\
\hline Programspan & 0.230 & $0.033^{* * *}$ \\
\hline Livestockholding & 0.46 & $0.025^{\star \star *}$ \\
\hline Totproduction & 0.730 & $1.44 \mathrm{NS}$ \\
\hline Creditaccess & 0.840 & $0.001^{*}$ \\
\hline Maleadult & 0.140 & $0.003^{*}$ \\
\hline Femaleadult & 0.256 & $0.985 \mathrm{NS}$ \\
\hline Familysize & -0.090 & $0.014^{* *}$ \\
\hline Literacy & 0.220 & $0.041^{* * *}$ \\
\hline Followup dummy & 0.410 & $0.004^{*}$ \\
\hline Savingexperience & 0.42 & $0.021^{* *}$ \\
\hline Pettytrading dummy & 0.110 & $0.032^{* *}$ \\
\hline -cons & 0.021 & $12.165 \mathrm{NS}$ \\
\hline \multicolumn{3}{|l|}{ Number of obs $=400$} \\
\hline \multicolumn{3}{|c|}{ LR chi2(24) $=121.65$} \\
\hline \multicolumn{3}{|c|}{ Prob> chi2 $=0.0000$} \\
\hline \multicolumn{3}{|c|}{ Pseudo R2 $=0.3523$} \\
\hline \multicolumn{3}{|c|}{ Log likelihood $=-64.5478$} \\
\hline \multicolumn{3}{|c|}{$\begin{array}{l}*,{ }^{* *},{ }^{* * *} \text { significant at } 1,5, \& 10 \text { percent, respectively and NS }= \\
\text { Not Significant }\end{array}$} \\
\hline \multicolumn{3}{|l|}{ Source: Author } \\
\hline
\end{tabular}

\section{Empirical results of the study}

The above table illustrates that the binary logistic regression estimates for program graduation dependent variable: whether a household graduates or not. There are might be multiple factors that affect graduation of Productive Safety Net Program beneficiary households thereby reducing the number of program participants in the program as a result can ensure food security. Based on the collected data and using the appropriate Econometrics model, Logit, the following analysis were drawn on the major graduation determinates of PSNP beneficiaries in the selected areas of the study and have been discussed here.

\section{Parameter estimates of Graduation Determinants of PSNP Beneficiaries}

Sex of household head (sex of $\mathrm{HH}$ ): A positive and significant relationship was found between sex of household 
head and the probability of a household being food selfsufficient. This means that the likelihood of graduation increases when the household head is male headed. In other words, male headed households are more likely to be graduate than female headed households. Women tend to be at a disadvantage because they are frequently limited to certain income-earning activities. It appears that households with cooperative men are more likely to succeed in the program. A male- head household has more probability of graduating and increases by 0.371 marginal effect.

Access to credit (Credit access): a household who access to credit and able to repay his/her loan 75 percent has more probability to be graduated. Statistically, there was significant different between program graduates and nongraduates at less than 10 percent level of significant. The likelihood of graduating for program participants increase by 0.84 marginal effects when a household has access to credit and able to repay the loan 75 percent. Households who have experience in the saving for the last five years and above have the probability of graduating sooner than those do have not by about 0.42 marginal effect. Statistically, there was significant different between program graduates and non-graduates at less than 5 percent level of significance.

Household participation in integrated agricultural package (intgagripackage): positive and significant relationship was found between integrated agricultural package and the probability of a household to graduate. This means that the likelihood of graduation increases with households' Participation in integrated agricultural packages. In other words, Participants are more likely to be graduate than non-participants. According to the findings of this study, the probability of household graduation increases by 0.53 marginal effects if they stay being participating in the program for more than three years in different household based packages.

Education (literacy): result indicated that households with better education have more likely to graduate than those not. According to the result, an improvement in education level defined by the shift in educational level from illiterate $(\mathrm{X}=0)$ to literate $(\mathrm{Xi}=1)$ results in increase in probability of a household to graduate by 0.22 marginal effects. Statistically, there was significant difference between the graduates and non-graduates at 10 percent level of significance.

Family size (familysize): household size is a continuous variable. Result shows that the probability of graduation decreases with an increase in family size. Each additional unproductive/dependent member of the household decreases the probability of graduation by 5 percent level of significance.

Petty trading (Pettytrading dummy): petty trading is a dummy variable 1 for program participants engaged in petty trading and 0 otherwise. A household who participated in the PSNP and has experiences on the petty trading for the last three years and above will have more probability of graduating. The result indicated that program participants who have three years and above in petty trading graduates sooner than those who don't. Statistically, there was significant mean difference between the graduates and non-graduates at 5 percent level of significance.

Livestock holding (Livestockholding): Program participants who have more of livestock measured in terms of TLU (Tropical Livestock Unit) have had more probability of graduation from the program. Statistically, there was significant mean difference between the graduates and non-graduates at less than 1 percent level of significance.

\section{Policy recommendations}

Based on the empirical findings made in the course of this study, the following policy recommendations are suggested. Because of variations in power of execution and nature of responsibilities of the stakeholders, the recommendations are presented under two levels: and household and community, \& government level

Recommendation from the Household and Community Level

- Improve the access to integrate agricultural packages so that to boost income of the program graduates.

- To encourage the local NGOs (REST) in following-up the program so that participants to graduate sooner and carried out other developmental activities.

- Program participants should be highly encouraged in other sources of income like petty trading and irrigation so that to boost their income and graduate sooner.

\section{Recommendations from the Government Level}

- As part of their graduation strategies, program participants should periodically be given graduation certificate by the government so that to facilitate monitoring and follow-up and to easily identify intervention to whom it deserves;

- the government instead of just focusing on graduating more and more of program participant, great attention should also be given program rejoining after graduation;

- program participants should exit the program when their declared per capita per year income passes the eligibility threshold level;

- as per the findings revealed that better to followed-up the program by NGOs than government for program participants so that to graduate more and sooner and as a result do other development activities which further enable them to declare food security and

- encouraging societal problem research works and dispatching the findings to the stakeholders like what have been studied here.

\section{Conclusion}

Chronic and transitory food insecurity is the most frequently observed challenges in Ethiopia in general and the study area in particular. Taking this into accounting, the current Ethiopian government took diverse development measures to alleviate the multifaceted problems faced the rural poor households with the aim to reduce poverty and food insecurity, one among the others is the productive safety net program (PSNP).

Regression results of the study revealed and came up with the following plausible conclusions: an introduction to integrated agricultural package use, male-headed household, age squared of the household, educational status of household heads, access to credit, exercising saving culture, male adults, NGOs follow-up (PSNP beneficiary households who were followed up/administered by NGOs like REST in this study), program benefit time (Program participants who have stayed in and benefited from program have more probability to graduate), access to petty trading and irrigation lead to program beneficiary households to have relatively greater probability of program graduation and these were statistically significant variables used to predict PSNP beneficiary households' graduation (TABLE 2). Therefore, to graduate the PSNP beneficiary 
households have to be ceaselessly supported all the way through other food security programs (like integrated agricultural program \& other development activities) to augment their source of income.

\section{References}

Arega, B. (2012). Productive Safety Nets Program and Household Level Graduation in Drought-Prone Areas of the Amhara Region of Ethiopia: A Case Study in Lay Gaint District. Ethiopian Journal of Environmental Studies and Management EJESM Vol. 5 no. 4 (Suppl.2) 2012.Ethiopian Journal of Environmental Studies and Management EJESM Vol. 5 no.4 (Suppl.2) 2012.

Ashenafi, A. (2011). Determinants of graduation from Productive Safety Net Program: A thesis submitted to Mekelle University in partial fulfillment of the requirements for the degree of Master of Science in Economics, Mekelle University, Ethiopia.

Assefa, D. (2002). An Empirical Analysis of Food Insecurity in Ethiopia: The case of Northern Wollo. African development, Vol.27:127-143.

Babatunde, R.O., Omotosho, O.A., and Sholotan, O.S. (2007).SocioEconomic Characteristics and Food Security Status of Farming Households in Kwara, North-Central, Nigeria.Pakistan Journal. 6(1), 49-58.

Damodar N. Gujirati, Dawn C. Poter and SangeetharGunasekar (2009). Basic Econometrics 5thed.

Devereux, S., Sabates-Wheeler.R., Tefera, M., and Taye, H. (2006). Ethiopia's Productive Safety Net Program. Trends in PSNP Transfers within Targeted Households. Report for DFID Ethiopia, Institute of Development Studies. Brighton.

Ethiopia PSNP.(2006). Trends in PSNP Transfers within Targeted Households.Discussion draft, Institute of Development Studies, Sussex, UK Indak International, Addis Ababa, Ethiopia.

Farrington, J., Sharp, K. and Sioblom, D. (2007). Targeting Approaches to Cash Transfers: Comparisons across Cambodia, India and Ethiopia. Social Cash Transfer Services, ODI, Western Bridge Road, UK.

Jeffrey M. Woodridge (2009). Introductory Econometrics.A Modern Approach 2nd Ed. The MIT Press Cambridge, Massachusetts London, England.

Gilligan, D.O., Hoddinott, J., Seyoum, A.T. (2008). The impact of Ethiopia's Productive Safety Net Program and its Linkages. Journal of Development Studies, 45(10), 1684-1706.

Government of Ethiopia.(2004). Productive Safety Net Program, Program Implementation Manual.Ministry of Agriculture and Rural Development. Addis Ababa, Ethiopia.

Hoddinott, J. (2011), Evaluation of Ethiopia's Food Security Program: Documenting Progress in the Implementation of PSNP and the Household Asset Building Program. Washington D.C, USA.

MoARD (2007). Productive Safety net Program, Graduation Guideline Note, Ministry of Agriculture and Rural Development, December 2007 Addis Ababa, Ethiopia.

Nigussa, F., and Mberengwa, I. (2009).Challenges of Productive Safety Net Program Implementation at local level.The case of Kuyuworeda, North Shewa zone, Oromia region, Ethiopia.Journal of Sustainable Development in Africa, 11(1), 248-267. Ethiopia.

PSNP-PIM (2007).Food security program logical framework. Addis Ababa: Ramakrishna, G, and Samuel, G. (2006). Future Agriculture Correspondence to Ethiopia, proceeding, March 2006.

Slater et al., (2006). Ethiopia Productive Safety Net Program (PSNP): PSNP Policy, Program and Institutional Linkages. London and Bristol, UK and Addis Ababa, Ethiopia: Overseas Development Institute, the IDL group and Indak International Pvt. L. C.

TFSCO. (2008). Tigrai Food Security Coordination Office, Productive Safety Net Program Annual Report 2008.

Yibrah, H. (2010). Impact of Productive Safety Net Program on Rural Households Assets' Protection and Consumption. A thesis submitted to Mekelle University in partial fulfillment of the requirements for the degree of Master of Science in Economics (Development policy Analysis), Mekelle University, Ethiopia. 